\title{
Quantitative Morphometric Analysis of the Pulmonary Arteries in Two Patients with D- Transposition of the Great Arteries and Persistence of the Fetal Circulation
}

\author{
MACDONALD DICK, II,${ }^{(45)}$ KATHLEEN HEIDELBERGER, DENNIS CROWLEY, \\ AMNON ROSENTHAL, AND PAUL HEES \\ Sections of Pediatric Cardiology and Pathology, C. S. Mott Children's Hospital and the Departments of Pediatrics and \\ Pathology, University of Michigan Medical School, Ann Arbor, Michigan, USA
}

\begin{abstract}
Summary
Quantitative morphometric studies were performed on the pulmonary arteries of two newborns who died at 1 and 3 days of age with both transposition of the great arteries and persistence of the fetal circulation. Similar studies were performed on two normal control subjects (age 2 and 6 days), one newborn infant (age 1 day) with secondary persistence of the fetal circulation, and one newborn infant (age 2 days) with isolated D-transposition of the great arteries. Morphometric data, summarized herein, showed greatest mean percent wall thickness in the patients with persistent fetal circulation either alone or with D-transposition of the great arteries, as compared to those without it. When wall thickness was related to external diameter of the vessel, the greatest difference in thickness was observed in the smallest vessels $(<150 \mu$ in diameter). Extension of smooth muscle peripherally and to the smallest vessels $(<50 \mu)$ was similarly most marked in those infants with persistence of the fetal circulation, either secondary or with D-transposition of the great arteries. Alevolar/artery ratio determinations were similar among the six subjects. These comparative data indicate that cyanotic congenital heart disease and persistence of the fetal circulation may coexist but at the same time be unrelated in a single patient. Furthermore when such coexistence is unrecognized, pharmacologic manipulation of the ductus arteriosus may be hazardous.
\end{abstract}

\section{Speculation}

Increased pulmonary arterial muscle similar to that seen in our two patients has been associated with the abnoral hemodynamics found in infants with hypoplastic left heart syndrome, aortic stenosis, and coarctation of the aorta. In contrast to these conditions we speculate that the increased muscle in the pulmonary arteries observed in our two patients was independent of D-transposition anatomy and its associated pathophysiology. Both adult and neonatal rats exposed to either environmental hypoxia or, in a latter case, maternal hypoxia develop increased muscle in the pulmonary arteries. These experimental models may be analogous to the two infants presented herein. In short, we strongly suspect that intrauterine hypoxia occurred in our two patients and may have been the stimulus producing the observed increase in muscle in their peripheral pulmonary arteries and resulting in, postnatally, persistence of the fetal circulation.

Sustained, but usually reversible, postnatal pulmonary arterial hypertension and right to left shunting at the atrial and ductal levels, called persistence of the fetal circulation (PFC) $(1,8,25$, 41 ) is a recognized disorder of the circulation in neonates with structurally normal hearts, and is associated with a variety of clinical presentations $(1,23)$. This report documents persistence of the fetal circulation in two infants with transposition of the great arteries and intact ventricular septum (D-TGA with IVS), and delineates, by means of quantitative morphometric analysis of the pulmonary arteries (3) increased muscularity within the peripheral arteries similar to that encountered in infants with secondary PFC $(15,29)$.

\section{MATERIALS AND METHODS}

\section{CASE REPORT}

Patient 1 (M.S. reg. no. 15346978 ) weighed $4.2 \mathrm{~kg}$ at birth after a 42-week gestation. Caesarian section was performed because of fetal bradycardia. At birth the infant had a heart rate of 60 beats per minute and required temporary intubation, oxygen, and assisted ventilation. At $48 \mathrm{hr}$ of age persistent cyanosis $\left(\mathrm{PO}_{2}\right.$ $=21 \mathrm{~mm} \mathrm{Hg}$ ) was noted; the cardiovascular examination, chest radiograph, and electrocardiogram were normal. Left ventricular biplane cineangiography confirmed D-TGA with IVS and anatomic right to left shunting through the patent ductus arteriosus. Balloon atrial septostomy produced a transient rise in systemic oxygen saturation from 49 to $81 \%$. Intracardiac pressure recordings revealed systolic pressure in the main pulmonary artery and left ventricle equal to greater than that in the aorta (Table 1). Systemic arterial saturation varied widely from 40 to $91 \%$ and was dependent upon the site of sampling (above or below the ductus) and the degree of patency of the ductus arteriosus.

The presence of right to left ductal shunting on the left ventricular angiogram, higher arterial oxygen saturation below the ductus, and suprasystemic pressures in the pulmonary artery suggested that the pulmonary vascular resistance was abnormally increased. Tolazoline $(1 \mathrm{mg} / \mathrm{kg})$ was infused into the pulmonary artery with no change in pulmonary arterial pressure. Sodium bicarbonate administration tended to be followed by a slight increase in systemic arterial saturation above the ductus. Prostaglandin E-1 infusion $(0.1 \mu \mathrm{g} / \mathrm{kg} / \mathrm{min})$ in the main pulmonary artery and at the systemic end of the patent ductus tended to decrease arterial saturation above the ductus. Surgical septectomy was unsuccessful and the infant expired.

Patient 2 (G.W. reg. no. 15229317 ) weighed $3 \mathrm{~kg}$ at birth after a 40-week uncomplicated pregnancy. The infant had an Apgar score of two at both 1 and $5 \mathrm{~min}$. Despite maximal ventilatory support and after a trial of both digoxin and tolazoline the infant remained hypoxic and acidotic. Systemic arterial $\mathrm{pH}$ was 7.29, $\mathrm{PCO}_{2} 36 \mathrm{~mm} \mathrm{Hg}$, and $\mathrm{Po}_{2} 17 \mathrm{~mm} \mathrm{Hg}$. At cardiac catheterization systolic and mean pulmonary artery pressures were consistently equal to aortic pressures (Table 1). Biventricular biplane angiography confirmed the pressure of D-TGA with IVS and demon- 
strated a patent ductus arteriosus with anatomic right to left shunting. A balloon atrial septostomy produced an initial rise in the systemic arterial oxygen saturation from 48 to $75 \%$; despite this initial improvement, refractory hypoxemia $\left(\mathrm{Po}_{2}=14 \mathrm{~mm} \mathrm{Hg}\right.$, $\mathrm{PCO}_{2}=29 \mathrm{~mm} \mathrm{Hg}$ ) and acidosis $(\mathrm{pH}=7.16)$ developed. Tolazoline infused into the pulmonary artery and emergency Mustard operation were unsuccessful and the patient expired.

There was no history of maternal indomethacin or aspirin ingestion in either patient $(23,24,36)$.

\section{METHODS}

Complete postmortem examination (Table 2) was performed in each patient. The pulmonary artery was injected with a mixture of barium sulphate and gelatin. The bronchi were infused with $10 \%$ formalin to expand the lungs. Random tissue sections of the fixed lung were stained with hematoxylin and eosin, Verhoeff's elastic, and Mallory's trichrome stains.

The resulting slides were examined using the quantitative morphometric analysis of Davies and Reid (3) and Haworth and Reid (15). A calibrated eyepiece was used to measure (1) external diameter of arteries; the distance between external elastic lamina across the shorter axis of the vessel; and (2) the medial wall thickness; the distance between the internal and external elastic lamina on each side of the vessel at the diameter. These measurements were used to calculate percent wall thickness:

$$
\frac{2 \times \text { mean medial wall thickness }}{\text { external diameter }} \times 100=\% \text { wall thickness }
$$

Also noted was the structure of the vessel wall, (i.e., muscular, partially muscular and nonmuscular) and the location of the artery with respect to its accompanying airway (pre-acinar bronchus, terminal bronchiole, respiratory bronchiole, alveolar duct, and alevolar wall). The number of alveoli and arteries per 10 consecutive high power fields was counted and expressed as a simple ratio of alveoli to artery. Muscularity was assessed on the basis of percent wall thickness and the extension of smooth muscle into smaller and more peripheral arteries.

The pulmonary arteries of four newborn infants serving as comparison patients were examined in a similar manner. Two were infants without pathologic evidence for primary pulmonary or cardiac disease (control patients). Control patient 1 had no clinical history of cardiorespiratory abnormalities. Control patient 2 had bilateral tension pneumothoraces identified at birth after footling breach extraction. Mechanical ventilation was begun and the initial abnormal arterial blood gas $\left(\mathrm{pH} 6.9 ; \mathrm{Po}_{2}, 32 \mathrm{~mm} \mathrm{Hg}\right.$; $\left.\mathrm{PCO}_{2} 68 \mathrm{~mm} \mathrm{Hg}\right)$ were restored to normal $\left(\mathrm{pH} \mathrm{7.38} ; \mathrm{Po}_{2} 54 \mathrm{~mm}\right.$ $\mathrm{Hg} ; \mathrm{PCO}_{2} 31 \mathrm{~mm} \mathrm{Hg}$ ). At autopsy the lungs were of normal weight and normal configuration, with the normal number of alveoli and arteries determined by morphometric analysis.

The third was a newborn infant with isolated D-TGA, and the fourth, a child with secondary PFC associated with meconium aspiration. Seventy-eight to 222 (mean $=160)$ vessels were analyzed in each patient. Mean percent wall thickness was calculated for each patient (Table 3), and plotted against vessel size $(50-\mu$ intervals, Fig. 1). Percent muscle extension was also related to both vessel size (Table 3) and accompanying airways at the periphery of the pulmonary arterial tree (Fig. 2).

Table 1. Hemodynamic data

\begin{tabular}{|c|c|c|c|c|c|c|c|c|c|}
\hline & & & $\begin{array}{c}\text { AAo } \\
\mathrm{O}_{2} \\
\end{array}$ & $\begin{array}{l}\text { sat } \\
(\%) \\
\end{array}$ & $\begin{array}{c}\text { DAo } \\
\mathrm{O}_{2}\end{array}$ & $\begin{array}{l}\text { sat } \\
(\%)\end{array}$ & $\begin{array}{c}\mathrm{P}_{\mathrm{AAo}} \\
\mathrm{mm} \mathrm{Hg}\end{array}$ & $\begin{array}{c}\mathrm{P}_{\mathrm{PA}} \\
\mathrm{mm} \mathrm{Hg}\end{array}$ & $\begin{array}{c}\text { Age at } \\
\text { catheterization }\end{array}$ \\
\hline \multicolumn{3}{|c|}{ D-TGA with PFC ${ }^{1}$} & No. 1 & No. 2 & No. 1 & No. 2 & & & \\
\hline \multirow[t]{3}{*}{ Patient 1} & $\mathrm{FIO}_{2} 1.0$ & $7.01-7.29$ & 70 & 49 & 78 & 70 & $85 / 56$ & & 64 hours \\
\hline & Tolazoline & & & & & & $79 / 56$ & $121 / 68$ & \\
\hline & Prostaglandin E-1 & 7.43 & 59 & & & & $82 / 53$ & - & \\
\hline Patient 2 & $\mathrm{FIO}_{2} 1.0$ & 7.10 & 48 & 63 & 53 & 76 & $57 / 35$ & - & 33 Hours \\
\hline \multirow[t]{2}{*}{ D-TGA } & $\mathrm{FrO}_{2} 1.0$ & 7.18 & 32 & & & & $58 / 32$ & - & 24 Hours \\
\hline & Septostomy & 7.30 & 64 & & & & $59 / 34$ & - & \\
\hline
\end{tabular}

'Abbreviations: $\left.\begin{array}{l}\text { AAo, asceinding aorta } \\ \text { DAo, descending aorta }\end{array}\right\}$ paired samples 1 and 2; D-TGA, dextro (complete) transposition of the great arteries; FIO 2 , fraction of inspired oxygen; $\mathrm{O}_{2}$ sat, oxygen saturation; $\mathrm{P}_{\mathrm{AAo}}$, pressure in ascending aorta; $\mathrm{PFC}$, persistence of the fetal circulation; $\mathrm{P}_{\mathrm{PA}}$, pressure in pulmonary artery.

Table 2. Autopsy data

\begin{tabular}{|c|c|c|c|c|}
\hline & \multirow{2}{*}{ Heart } & Lungus & \multirow{2}{*}{ Brain } & \multirow{2}{*}{ Other } \\
\hline & & Routine histology & & \\
\hline \multicolumn{5}{|c|}{ D-TGA with PFC ${ }^{1}$} \\
\hline Patient 2 & D-TGA with IVS & Unremarkable & $\begin{array}{l}\text { Diffuse subarachnoid hemorrhage } \\
\text { intraventricular hemorrhage }\end{array}$ & $\begin{array}{l}\text { Interatrial baffle (Mustard) } \\
\text { PDA ligation }\end{array}$ \\
\hline \multicolumn{5}{|l|}{ Control } \\
\hline Patient 1 & $\begin{array}{l}\text { Normal } \\
\text { PDA }(10 \mathrm{~mm})\end{array}$ & $\begin{array}{l}\text { Focal interstitial hemorrhages } \\
\text { well aerated }\end{array}$ & No significant abnormality & $\begin{array}{l}\text { Ornithine transcarbamylase defi- } \\
\text { ciency }\end{array}$ \\
\hline Patient 2 & Normal & Acute passive congestion & No significant abnormality & Lethal neonatal dwarfism \\
\hline
\end{tabular}

\footnotetext{
'Abbreviations: D-TGA dextro (complete) transposition of the great arteries; IVS, intact ventricular septum; PDA, patent ductus arteriosus, PFC,
} persistence of the fetal circulation. 
Table 3. Morphometric data

\begin{tabular}{|c|c|c|c|c|c|c|}
\hline & \multicolumn{2}{|c|}{ D-TGA $\overline{\mathrm{c}} \mathrm{PFC}^{1}$} & \multirow{2}{*}{ PFC } & \multirow{2}{*}{ D-TGA } & \multicolumn{2}{|c|}{ Control } \\
\hline & No. 1 & No. 2 & & & No. 1 & No 2 \\
\hline Age (days) & 3 & 1 & 2 & 1 & 2 & 6 \\
\hline $\begin{array}{c}\text { WT }(\%) \\
(n)\end{array}$ & $\begin{array}{c}7.7 \pm 3.1 \\
(78)\end{array}$ & $\begin{array}{c}8.3 \pm 2.8 \\
(195)\end{array}$ & $\begin{array}{c}7.4 \pm 1.6 \\
(222)\end{array}$ & $\begin{array}{c}5.1 \pm 1.9 \\
(130)\end{array}$ & $\begin{array}{c}4.9 \pm 2.4 \\
(190)\end{array}$ & $\begin{array}{c}3.2 \pm 1.1 \\
(144)\end{array}$ \\
\hline $\begin{array}{c}\operatorname{ExSM}(\%) \\
(\mathrm{N})\end{array}$ & 100 & $\begin{array}{c}67 \\
(116)\end{array}$ & $\begin{array}{c}67 \\
(151)\end{array}$ & $\begin{array}{c}39 \\
(61)\end{array}$ & $\begin{array}{c}43 \\
(116)\end{array}$ & $\begin{array}{c}13 \\
(45)\end{array}$ \\
\hline $\mathrm{A} / \mathrm{a}$ & $19: 1$ & $23: 1$ & $19: 1$ & $20: 1$ & $20: 1$ & $21: 1$ \\
\hline
\end{tabular}

Abreviations: A/a, alveolar/arterial ratio; D-TGA, D-transposition of the great arteries; D-TGA $\bar{c}$ PFC, D-transposition of the great arteries with persistence of the fetal circulation; ExSM, extension of smooth muscle-expressed as a percent of arteries equal to or less than $50 \mathrm{u}$ in diameter with either complete or partially muscularized walls; PFC, persistence of the fetal circulation; WT, Wall thickness (vessels $\leq 400 \mathrm{u}$ diameter; see text); mean and S.D.

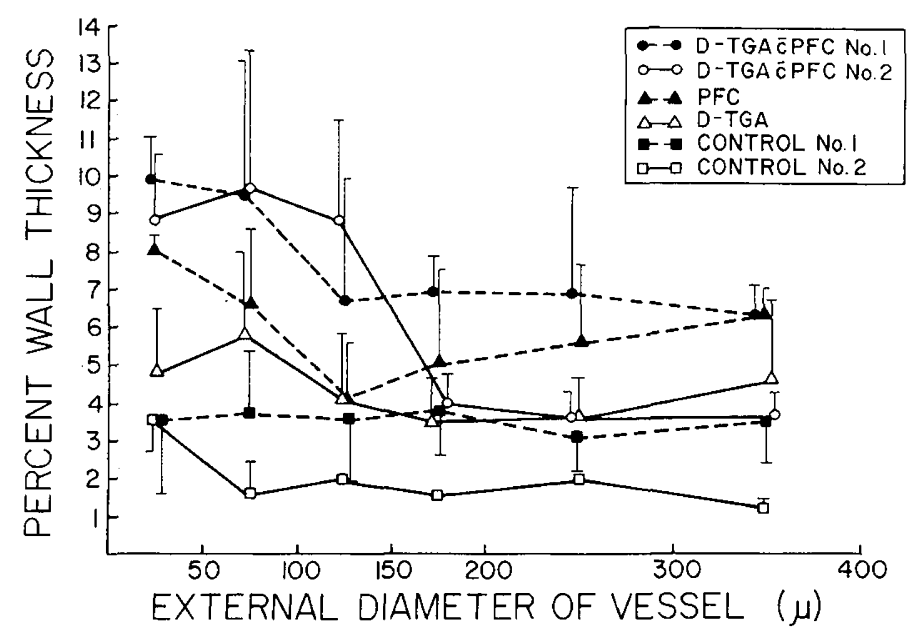

Fig. 1. Percent wall thickness of arteries (mean \pm S.D.) related to external diameter in $\mu$. D-TGA, dextro (complete)-transposition of the great arteries; PFC, persistence of the fetal circulation.
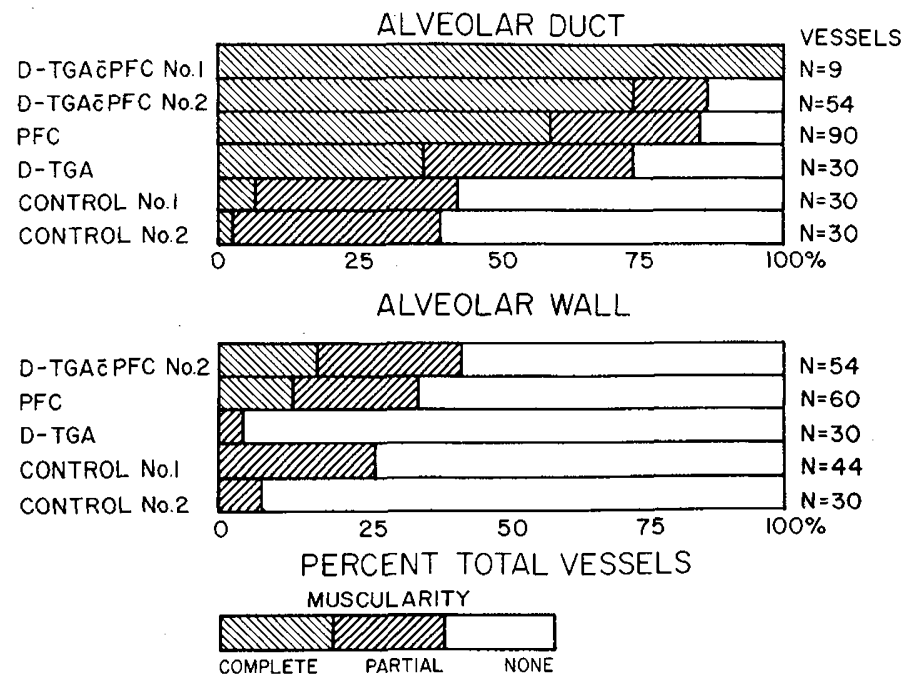

Fig. 2. Extension of smooth muscle (partial and complete) into the alveolar duct and alveolar wall arteries in the six patients. No alveolar wall arteries were identified in the lungs of D-TGA with PFC patient 1, probably because they were severely thickened, constricted and perhaps obliterated (30) and thus were not perfused by the barium-gelatin injection. (Abbreviations-see Fig. 1.)

\section{RESULTS}

Table 2 summarizes the pathologic findings in both the study and comparison patients. None of the pulmonary arteries among the six subjects exhibited either Heath-Edwards (17) changes greater than stage 1 (medial thickening) or microthrombi.
The morphometric data obtained from the analysis of the pulmonary arteries of the six patients are summarized in Table 3. The mean wall thickness is greatest in arteries of the patients with D-TGA and PFC, decreasing in successive order in the arteries of the patients with secondary PFC, isolated D-TGA, and normal hearts and lungs. The mean wall thicknesses of the pulmonary arteries of the two study patients resemble most closely that found in the patient with secondary PFC. In contrast the vessels of the patient with isolated D-TGA are similar to those found in the two control patients.

When wall thickness is related to external diameter (Fig. 1) the difference in wall thickness is most evident in the smallest vessels. At arterial size $<150 \mu$, the pulmonary arterial wall thicknesses of the two study patients are greater than the wall thicknesses of the other four patients. Among other vessels sizes study patient 1 and the patient with secondary PFC exhibited similar wall thicknesses; the remaining four patients display much thinner arterial medial walls.

Smooth muscle extended into more arteries less than $5.1 \mu$ of both the study patients and the secondary PFC patient than into those of both the isolated D-TGA patient and the controls (Table 3). Between 51 and $100 \mu$, the D-TGA with PFC patients, the secondary PFC patient, and the D-TGA patient all had a mixed population of partially and totally muscularized arteries. When arteries $\geq 200 \mu$ in diameter were examined, muscularization involved $100 \%$ of arteries in all patients examined. Extension of smooth muscle is related in Figure 2 to the two most peripheral sites along the accompanying airway: the alveolar duct and alveolar wall. Partial and complete smooth muscle extension along the arterial pathway was virtually identical between the D-TGA with PFC patients and the secondary PFC patient. In contrast the alveolar duct and alveolar wall arteries of the isolated D-TGA patient and the control patients were much less muscularized.

Alveolar/artery ratio determinations were similar among the six infants indicating a normal number of arteries in the lungs of the four noncontrol subjects (32).

\section{DISCUSSION}

The two neonates described herein fulfill the criteria for the clinical diagnosis of persistence of the fetal circulation $(1,8,23$, 25,41 ) in the presence of transpositon of the great arteries. Similar clinical and hemodynamic features have previously been described in neonates with transposition; routine histologic examination of the lungs in three of the four infants, who died, one at age 2 months, disclosed variable degrees of intimal and medial thickening (14). However, importantly, no data regarding the morphology of the pulmonary arteries of infants with D-TGA and IVS expiring within the first $72 \mathrm{hr}$ of life are available using the technique of Davies and Reid (3) and Haworth and Reid (15).

The detailed morphometric analysis of the pulmonary arterial tree in our two study patients disclosed structural abnormalities consisting of extension of smooth muscle to the alveolar wall and alveolar duct vessels and increased vessel wall thickness in the small arteries of lung, especially those $<150 \mu$ in diameter. Similar findings of increased peripheral muscularity with normal numbers of arteries were observed not only in our patient with isolated PFC but also in nine PFC patients described by others $(15,29)$. These arterial wall changes exceed those found not only in agematched controls $(3,38)$, but also those found in our D-TGA patient, and therefore support the hypothesis (15) that the anatomic correlate of the PFC syndrome is an increased amount of medial muscle manifested as increased wall thickness and extension of smooth muscle to distal arteries.

The etiology of these structural changes is unknown. A causal relationship in our two patients occurring during gestation between D-TGA on the one hand and the observed morphologic changes leading to the postnatal pathophysiology of PFC on the other is improbable. Patients with D-TGA and IVS have been shown, using different techniques, to exhibit, within the first 10 days of life, pulmonary arteries similar to those of normal newborn 
infants (6), and have not been reported to develop significant (greater than grade II) pulmonary vascular obstructive disease (17) before 6 weeks of age $(5,26,33,34,42,43)$. In addition, although infants with hypoplastic left heart syndrome, aortic stenosis, or coarctation of the aorta (both naturally occurring and experimentally produced) may exhibit similar or greater degrees of muscle wall thickening and extension to distal arteries $(16,26$, 31 ), pathologic, experimental, and theoretical considerations suggest that the fetal circulation pattern in these conditions may be associated with abnormally elevated left ventricular, left atrial, and pulmonary arterial pressure which may give rise to increased pulmonary vascular resistance (31). In sharp contrast to that fetal pathophysiology, infants with D-TGA and IVS manifest fetal cardiopulmonary hemodynamics which promote, at least theoretically, a reduction in fetal pulmonary vascular resistance (40). Therefore, the demonstration of markedly thickened arterial walls in the small arteries $(<150 \mu)$ at the periphery of the lungs in the D-TGA with PFC patients and the isolated PFC patient at 1 to 3 days of age, in comparison to its absence in our age-matched controls, including an isolated D-TGA patient, argues strongly for other prenatal intrauterine factor(s) in the genesis of PFC.

Based on experimental evidence $(11,19,30,37)$ intrauterine hypoxia has been advanced as one of the several mechanisms, recently summarized (25), which could account for the observed increase in distal muscularity. The presence of intrauterine hypoxia in both of our patients is supported by the marked distress observed at birth and the central nervous system hemorrhage (13) found at necropsy. Murine models have demonstrated increased peripheral muscularity and enhanced cellular differentiation into muscle among cells lining the distal pulmonary arterial pathway in response to environmental hypoxia $(18,19,30,37)$. Newborn rats whose mothers were exposed to environmental hypoxia in the later stages of pregnancy exhibited increased medial thickness in small $(<150 \mu)$ pulmonary vessels compared to controls (12). Prenatal hypoxemia produced by experimental asphyxiation has also been shown to increase lamb ductal right to left shunting presumably in an induced and prolonged pulmonary arterial vasoconstrictor response (9). The presence of increased peripheral arterial muscle, perhaps as a consequence of intrauterine hypoxemia, along with an exaggerated postnatal hypoxemic-induced vasoconstriction, may have produced an adverse, self-propagating cycle of increasing pulmonary vascular resistance, increasing pulmonary vasoconstrictions, right to left ductal shunting and increasing hypoxemia. Thus intrauterine hypoxia may have been an important factor in the development of both the morphometric changes and the pathophysiology of persistence of the fetal circulation in our two patients.

The presence of two pathophysiologic states, D-TGA physiology with parallel circulations and PFC, in the same patient renders management of each extremely difficult and may account for a number of D-TGA patients who are refractory to the usual treatment. Creation of an atrial septal defect by balloon septostomy (39), in the absence of left atrial hypertension and interatrial pressure difference, and/or infusion of prostaglandin E-1 to dilate the ductus arteriosus $(4,22,32)$, may have negligible or even detrimental effects in those patients who also exhibit PFC by increasing atrial and ductal anatomic right to left shunting, increasing the amount of blood bypassing the lungs, and decreasing the systemic oxygen saturation. The waxing and waning of the arterial oxygen saturation (above the ductus) observed in our two patients may be explained by the variability in the pulmonary vascular resistance and the patency of the ductus arteriosus, responding to changing $\mathrm{Po}_{2}, \mathrm{pH}$ and $\mathrm{PGE}-1$ and bicarbonate infusions (Fig. 3). Based on clinical and experimental evidence (7, $9-11,27,35)$, oxygen administration and tolazoline, both potent pulmonary vasodilators, have been suggested as therapeutic agents designed to reduce pulmonary vascular resistance. Although these measures failed in these two infants, it seems prudent to attempt pulmonary vasodilatation by maximal oxygenation, reversal of acidosis, and administration of pulmonary vasodilators.

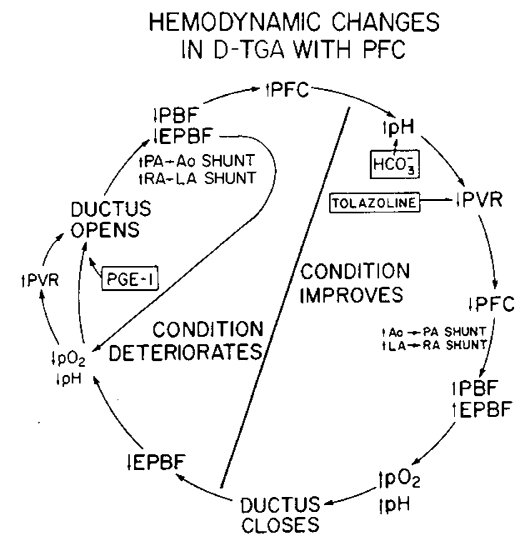

Fig. 3. Schematic diagram illustrating the adverse hemodynamic and metabolic cyclic relationship between transposition of the great arteries and persistence of the fetal circulation and their respective treatment. Factors (bicarbonate, pulmonary vasodilators, and oxygen), which decrease pulmonary vascular resistance and increase pulmonary blood flow, may result in a dominant effect of transposition, with closure of the ductus and poorer mixing. Factors that improve the D-TGA physiology such as opening of the ductus to increase effective pulmonary blood flow (mixing) would, in the presence of high pulmonary vascular resistance, facilitate ductal right to left shunting, resulting in a dominant effect of persistence of the fetal circulation, i.e., bypass of the lungs. (Abbreviations: Ao, aorta; D-TGA, D-transposition of the great arteries; EPBF, effective pulmonary blood flow; LA, left atrium; PA, pulmonary artery; PBF, pulmonary blood flow; PFC, persistence of the fetal circulation; PGE-1 prostaglandin E-1; PVR, pulmonary vascular resistance; RA, right atrium.)

Although prostaglandin E-1 has been shown to reduce the pulmonary vascular resistance in man and animal models $(2,20)$, preliminary studies suggest that prostaglandin E-1 fails to dilate the pulmonary vascular bed in newborn infants with PFC (28); therefore, as our experience suggests, the use of this substance in infants with D-TGA should be withheld until the possibility of associated PFC pathophysiology has been excluded by cardiac catheterization and angiography. This experience emphasizes the importance of avoiding trials of therapeutic agents designed to alter cardiopulmonary hemodynamics in cyanotic infants before excluding underlying congenital heart disease.

\section{REFERENCES AND NOTES}

1. Behrman, R. E.: Persistence of the fetal circulation. J. Pediatr., 89: 636 (1976).

2. Carlson, L. A., Ekelund, L., and Oro, L.: Circulatory and respiratory effects of different doses of prostaglandin E-1 in man. Acta Physiol. Scand., 75: 161 (1969).

3. Davies, G., and Reid, L.: Growth of the alveoli and pulmonary arteries in childhood. Thorax, 24: 669 (1962)

4. Driscoll, D. J., Kugler, J. D., Nihill, M. R., and McNamara, D. G.: The use of prostaglandin $\mathrm{E}$ in a critically ill infant with transposition of the great arteries. J. Pediatr., 95: 259 (1979).

5. Ferenz, C.: Transposition of the great vessels; pathophysiologic considerations based upon a study of the lungs. Circulation, 33: 232 (1966).

6. Ferguson, D. J., Adams, P., and Watson, D.: Pulmonary arteriosclerosis in transposition of the great vessels. Am. J. Dis. Child., 99: 653 (1960)

7. German, J. C., Partlett, R. H., Gazzanga, A. B., Huntable, R. F., Ambie, R., and Sperling, D. R.: Pulmonary artery pressure monitoring in persistent fetal circulation (PFC). J. Pediatr. Surg., 12: 913 (1979).

8. Gersony, W. M., Duc, G. V., and Sinclair, J. C.: PFC syndrome (persistence of the fetal circulation). Circulation, 40: 111 (1969).

9. Gersony, W. M., Morishima, H. O., Daniel, S. S., Kohl, S., Cohen, H., Brown, W., and James, L. S.: The hemodynamic effect of intrauterine hyoxia: an experimental model in newborn lambs. J. Pediatr., 89: 631 (1976).

10. Goetzman, B. W., and Milstein, J. M.: Pulmonary vasodilator action of tolazoline. Pediatr. Res., 13: 942 (1979)

11. Goetzman, B. W., Sunshine, P., Johnson, J. D., Wennberg, R. P., Hackel, A., Merten, D. F., Bartoletti, A. I., and Silverman, N. H.: Neonatal hypoxic and pulmonary vasospasm: response to tolazoline. J. Pediatr., 89: 617 (1976).

12. Goldberg, S. J., Levy, R. A., Siassi, B., and Belten, J.: Effects of maternal hypoxia and hyperoxia upon the neonatal pulmonary vasculature. Pediatrics, 48: 528 (1971).

13. Goldstein, G. W.: Pathogenesis of brain edema and hemorrhage: role of the brain 
capillary. Pediatrics, 64: 357 (1979).

14. Hawker, R. E., Freedom, R. M., Rowe, R. D., and Krovetz, L. J.: Persistence of the fetal pattern of circulation in transposition of the great arteries. Johns Hopkins Med. J., 134: 107 (1974).

15. Haworth, S. G., and Reid, L.: Persistent fetal circulation: newly recognized structural features. J. Pediatr., 88: 614 (1976).

16. Haworth, S. G., and Reid, L: Quantitative structural study of pulmonary circulation in the newborn with aortic atresia, stenosis or coarctation. Thorax, 32, 121 (1977).

17. Heath, D., and Edwards, J. E.: The pathology of hypertensive pulmonary vascular disease. A description of six grades of structural changes in the pulmonary arteries with special reference to congenital cardiac septal defects. Circulation, 18: 522 (1958).

18. Hislop, A., and Reid, L.: Changes in the pulmonary artery of the rat during recovery from hypoxia induced pulmonary hypertension. Br. J. Exp. Pathol. 58: 653 (1977)

19. Hislop, A., and Reid, L.: New findings in pulmonary arteries of rats with hypoxiainduced pulmonary hypertension. Br. J. Exp. Pathol., 57: 542 (1976).

20. Hyman, A. I., Spannhake, E. W., and Kadowitz, P. J.: Prostaglandins and the lung. Am. Rev. Respir. Dis., 117: 111 (1978)

21. Lakier, J. B., Stranger, P., Heymann, M. A., Hoffman, J. I. E, and Rudolph, A M.: Early onset of pulmonary vascular obstruction in patients with aortopulmonary transposition and intact ventricular septum. Circulation, 51: 875 (1975).

22. Lang, P., Freed, M. D., Perman, F. Z., Norwood, W. I., and Nadas, A. S.: Use of prostaglandin E- 1 in infants with D-transposition of the great arteries and intact ventricular septum. Am. J. Cardiol., 44: 76 (1979).

23. Levin, D. C.: Pulmonary pulmonary hypoplasia. J. Pediatr., 95: 550 (1979).

24. Levin, D. C., Fixler, D. E., Moriss, F. C., and Tyson, J.: Morphologic analysis of the pulmonary vascular bed in infants exposed in utero to prostaglandin synthetase inhibitors. J. Pediatr., 92: 478, 1978.

25. Levin, D. L., Heymann, M. A., Kitterman, J. A., Gersony, G. A., Phibbs, R. H., and Rubolph, A. M.: Persistent pulmonary hyertension of the newborn infant. J. Pediatr., 89: 626 (1976)

26. Levin, D. L., Mills, L. S., and Parkey, M.: Morphologic development of the pulmonary vascular bed in experimental coarctation of the aorta. Circulation 60: 349 (1979)

27. Loch, J. C., Coceani, F., and Olley, P.M.: Direct and indirect pulmonary vascular effects of tolazoline in the newborn lamb. J. Pediatr., 95: 600 (1979).

28. Murphy, J. D., Freed, M. D., Lang, P., Epstein, M., and Frantz, I.: Prostaglandin E-1 infusion in neonatal persistent pulmonary hypertension. Pediatr. Res., 14 11 (1980).

29. Murphy, J. D., Rabinovitch, M., Goldstein, J., and Reid, L. M.: Structural basis of neonatal persistent pulmonary hypertension. Pediatr. Res., 14: 607 (1980).

30. Myerick, B., and Reid, L.: The effect of continued hypoxia on rat pulmonary arterial circulation. An ultrastructural study. Lab. Invest., 38: 188 (1978).

31. Neumann, M. P., Heidelberger, K. P., Dick, M., Rosenthal, A.: Pulmonary vascular changes associated with hypoplastic left ventricular syndrome. Pediatr. Cardiol., (in press).

32. Neutz, J. M., Starling, M. B., Elliott, R. B., and Barratt-Boyes, E. B.: Palliation of cyanotic heart disease in infancy with E-type prostaglandins. Circulation, 55: 238 (1977)

33. Newfeld, E. A., Paul, M. H., Muster, A. J., and Idriss, F. S.: Pulmonary vascular disease in complete transposition of the great arteries: a study of 200 cases. Am. J. Cardiol., 34: 75 (1974).

34. Newfeld, E. A., Paul, M. H., Muster, A. J., and Idriss, F. S.: Pulmonary vascular disease in transposition of the great vessels and intact ventricular system. Circulation, 59: 525 (1979).

35. Peckham, G. J., and Fox, W. W.: Physiologic factors affecting pulmonary artery pressure in infants with persistent pulmonary hypertension. J. Pediatr., 93: 1005 (1978).

36. Perkins, R. M., Levin, D. L., and Clark, R.: Serum salicylate levels and right to left ductus shunts in newborn infants with persistent pulmonary hypertension J. Pediatr., 96: 721 (1980).

37. Rabinovitch, M., Fisher, I. C., Gamble, W. J., Reid, L., and Treves, S.: Quantitation of right ventricular hypertrophy with thallium-201 in chronically hypoxic rats. Pediatr. Res., 11: 397 (1977).

38. Rabinovitch, M., Haworth, S. G., Castaneda, A. R., Nadas, A. S., and Reid, L. M.: Lung biopsy in congential heart disease: a morphometric approach to pulmonary vascular disease. Circulation, 58 : 1107 (1978).

39. Rashkind, W. J., and Miller, W. W.: Creation of an atrial septal defect without thoractomy. A palliative approach to complete transposition of the great arteries. J. Am. Med. Assoc., 196: 991 (1966).

40. Rudolph, A. M.: Congenital Disease of the Heart. pp. 466-475 (Year Book Medical Publishers, Chicago, 1974)

41. Siassi, B., Goldberg, S. J., Emmanouilides, G. C., Higashino, S. M., and Lewis, E.: Persistent pulmonary hypertension of the newborn infant. J. Pediatr., 89: 626 (1976).

42. Viles, P. H., Ongley, P. A., and Titus, J. L.: The spectrum of pulmonary vascular disease in transposition of the great arteries. Circulation, 40: 31 (1969).

43. Wagenvoort, C. A., Nauta, J., Van der Schur, P. J., Weeda, H. W. H., and Wagenvoort, $\mathrm{N}$.: The pulmonary vasculature in complete transposition of the great vessels, judged from lung biopsies. Circulation, 38: 746 (1968).

44. The authors are grateful for the excellent secretarial assistance of Ellen Clark.

45. Requests for reprints should be addressed to: Macdonald Dick, M.D., F1123, Section of Pediatric Cardiology, C. S. Mott Children's Hospital, University of Michigan, 1405 East Ann Street, Ann Arbor, MI 48109 (USA)

46. This research was supported by a grant from the Michigan Heart Association.

47. Received for publication December 16, 1980

48. Accepted for publication March 13, 1981. 